\title{
Endocannabinoids Mediate Presynaptic Inhibition of Glutamatergic Transmission in Rat Ventral Tegmental Area Dopamine Neurons through Activation of CB1 Receptors
}

\author{
Miriam Melis, ${ }^{1,2}$ Marco Pistis, ${ }^{1,2}$ Simona Perra, ${ }^{1,2}$ Anna Lisa Muntoni, ${ }^{1,3}$ Giuliano Pillolla, ${ }^{1,2}$ and Gian Luigi Gessa ${ }^{1,2}$ \\ ${ }^{1}$ Centre of Excellence, Neurobiology of Addiction, and 2B. B. Brodie Department of Neuroscience, University of Cagliari, Monserrato, 09042 Italy, and \\ ${ }^{3}$ Consiglio Nazionale delle Ricerche Institute of Neuroscience in Pisa, Section of Cagliari, c/o B. B. Brodie Department of Neuroscience, University of \\ Cagliari, Monserrato, 09042 Italy
}

\begin{abstract}
The endogenous cannabinoid system has been shown to play a crucial role in controlling neuronal excitability and synaptic transmission. In this study we investigated the effects of a cannabinoid receptor (CB-R) agonist WIN 55,212-2 (WIN) on excitatory synaptic transmission in the rat ventral tegmental area (VTA). Whole-cell patch clamp recordings were performed from VTA dopamine (DA) neurons in an in vitro slice preparation. WIN reduced both NMDA and AMPA EPSCs, as well as miniature EPSCs (mEPSCs), and increased the pairedpulse ratio, indicating a presynaptic locus of its action. We also found that WIN-induced effects were dose-dependent and mimicked by the CB1-R agonist HU210. Furthermore, two CB1-R antagonists, AM281 and SR141716A, blocked WIN-induced effects, suggesting that WIN modulates excitatory synaptic transmission via activation of CB1-Rs. Our additional finding that both AM281 and SR141716A per se increased NMDA EPSCs suggests that endogenous cannabinoids, released from depolarized postsynaptic neurons, might act retrogradely on presynaptic CB1-Rs to suppress glutamate release. Hence, we report that a type of synaptic modulation, previously termed depolarization-induced suppression of excitation (DSE), is present also in the VTA as a calcium-dependent phenomenon, blocked by both AM281 and SR141716A, and occluded by WIN. Importantly, DSE was partially blocked by the $\mathrm{D}_{2} \mathrm{DA}$ antagonist eticlopride and enhanced by the $\mathrm{D}_{2} \mathrm{DA}$ agonist quinpirole without changing the presynaptic cannabinoid sensitivity. These results indicate that the two pathways work in a cooperative manner to release endocannabinoids in the VTA, where they play a role as retrograde messengers for DSE via CB1-Rs.
\end{abstract}

Key words: cannabinoid receptor; dopamine; excitatory transmission; midbrain; retrograde signal; vanilloid receptor

\section{Introduction}

Excitatory synaptic input mediated by glutamate is a key component in the regulation of DA cell excitability (Overton and Clark, 1997). Ventral tegmental area (VTA) dopamine (DA) neurons receive glutamate afferents from three primary sources: the medial prefrontal cortex, the pedunculopontine region, and the subthalamic nucleus (Christie et al., 1985; Sesack and Pickel, 1992; Fallon and Loughlin, 1995; Taber et al., 1995). One role of the glutamatergic innervation to the VTA is to mediate a switch from pacemaker-like to burst-firing pattern in DA cells (Gariano and Groves, 1988; Svensson and Tung, 1989; Johnson et al., 1992; Murase et al., 1993; Zhang et al., 1994). Thus, modulation of glutamatergic transmission onto VTA DA cells seems to be important in DA-related functions and disorders (Grace, 1991; Wise, 1996; Schultz, 1998).

Presynaptic inhibition of glutamate release onto VTA neurons

Received 0ct. 3, 2003; revised Nov. 5, 2003; accepted Nov. 7, 2003

We thank Drs. Bjorn Schilstrom and Marco Diana for many helpful discussions and comments on this manuscript and William T. Dunn III for proofreading this manuscript.

Correspondence should be addressed to Miriam Melis, B. B. Brodie Department of Neuroscience, University of Cagliari, Cittadella Universitaria, 09042 Monserrato, Italy. E-mail: myriam@unica.it. DOI:10.1523/JNEUROSCI.4503-03.2004

Copyright $\odot 2004$ Society for Neuroscience $\quad$ 0270-6474/04/240053-10\$15.00/0 is mediated by activation of $\mathrm{GABA}_{\mathrm{B}}$, adenosine $\mathrm{A}_{1}$ (Wu et al., 1999), metabotropic glutamatergic (mGluR), and muscarinic $M_{3}$ receptors (Zheng and Johnson, 2003). Interestingly, cannabinoids have recently been revealed to mediate presynaptic inhibition of glutamate release in other brain regions (Shen et al., 1996; Szabo et al., 2000; Gerdeman and Lovinger, 2001; Huang et al., 2001; Kreitzer and Regehr, 2001; Huang et al., 2002; OhnoShosaku et al., 2002a,b; Azad et al., 2003), although their role in the VTA remains elusive.

Exogenous cannabinoids have been demonstrated to mimic the actions of two major putative endogenous ligands, anandamide (Devane et al., 1992) and 2-arachidonylglycerol (2AG) (Mechoulam et al., 1995; Sugiura et al., 1995, 1999), which are produced and released from neurons (Di Marzo et al., 1998; Piomelli et al., 2000). Activation of CB-Rs exerts several effects, including inhibition of voltage-gated $\mathrm{Ca}^{2+}$ channels and activation of inwardly rectifying $\mathrm{K}^{+}$-channels (Di Marzo et al., 1998; Felder and Glass, 1998), therefore, endocannabinoids seem to play an important role in controlling neuronal excitability and synaptic transmission. Indeed, recent studies have clarified that endogenous cannabinoids act retrogradely onto CB1-Rs in the presynaptic membrane and suppress transmitter release (Kreitzer and Regehr, 2001; Maejima et al., 2001; Ohno-Shosaku et al., 2001; 
Wilson and Nicoll, 2001; Wilson et al., 2001; Kreitzer et al., 2002; Brenowitz and Regehr, 2003; Brown et al., 2003; Ohno-Shosaku et al., 2003; Trettel and Levine, 2003).

CB1-Rs are so far the only cloned CB-R type in the neurons of the CNS (Matsuda et al., 1990). These receptors have been recently found to be colocalized with tyrosine hydroxylase (TH)positive neurons in the midbrain (Wenger et al., 2003), where high levels of anandamide (Marinelli et al., 2003) and moderate immunoreactivity for the enzyme fatty acid amidohydrolase (FAAH), key in the termination of endocannabinoid signaling (Deutsch et al., 2001), were detected (Romero et al., 2002). Additionally, exogenous cannabinoids have extensively been shown to affect neuronal activity of VTA DA cells (French, 1997; Gessa et al., 1998; Szabo et al., 2002; Cheer et al., 2003; Patel and Hillard, 2003).

Ergo, we investigated the possibility that cannabinoids might affect excitatory synaptic transmission onto VTA DA cells.

\section{Materials and Methods}

Slice preparation. All experiments followed international guidelines on the ethical use of animals from the European Communities Council (EEC) Directive of November 24, 1986 (86/609/EEC).

The preparation of VTA slices was as described previously (Bonci and Malenka, 1999).

Briefly, male Sprague Dawley rats (14-21 d; Harlan Nossan, Italy) were anesthetized with halothane and killed. A block of tissue containing the midbrain was rapidly dissected and sliced in the horizontal plane ( 300 $\mu \mathrm{m})$ with a vibratome (Campden Instruments, Loughborough, UK) in ice-cold low-Ca ${ }^{2+}$ solution containing (in $\mathrm{mm}$ ): $126 \mathrm{NaCl}, 1.6 \mathrm{KCl}, 1.2$ $\mathrm{NaH}_{2} \mathrm{PO}_{4}, 1.2 \mathrm{MgCl}_{2}, 0.625 \mathrm{CaCl}_{2}, 18 \mathrm{NaHCO}_{3}$, and 11 glucose. Slices (three per animal) were transferred to a holding chamber with artificial CSF (ACSF; $37^{\circ} \mathrm{C}$ ) saturated with $95 \% \mathrm{O}_{2}$ and $5 \% \mathrm{CO}_{2}$ containing (in $\mathrm{mm}$ ): $126 \mathrm{NaCl}, 1.6 \mathrm{KCl}, 1.2 \mathrm{NaH}_{2} \mathrm{PO}_{4}, 1.2 \mathrm{MgCl}_{2}, 2.4 \mathrm{CaCl}_{2}, 18$ $\mathrm{NaHCO}_{3}$, and 11 glucose. Slices were allowed to recover for at least $1 \mathrm{hr}$ before being placed, as hemislices, in the recording chamber and superfused with the ACSF $\left(34-36^{\circ} \mathrm{C}\right)$ saturated with $95 \% \mathrm{O}_{2}$ and $5 \% \mathrm{CO}_{2}$.

Whole-cell recording. Cells were visualized with an upright microscope with infrared illumination (Axioskop FS 2 plus; Zeiss, Oberkochen, Germany), and whole-cell voltage-clamp recordings were made by using an Axopatch 200B amplifier (Axon Instruments, Foster City, CA). For BAPTA experiments, EPSC recordings were made with electrodes filled with a solution containing the following (in $\mathrm{mM}$ ): $117 \mathrm{Cs}$ methanesulfonic acid, 20 HEPES, $15 \mathrm{Cs}_{4}$-BAPTA, 0.4 EGTA, $2.8 \mathrm{NaCl}, 5$ TEA-Cl, 2.5 $\mathrm{Mg}_{2} \mathrm{ATP}$, and $0.25 \mathrm{Mg}_{2} \mathrm{GTP}$, pH 7.2-7.4, 275-285 mOsm. All other EPSC recordings were made with electrodes filled with a solution containing the following (in $\mathrm{mM}$ ): 117 Cs methanesulfonic acid, 20 HEPES, 0.4 EGTA, $2.8 \mathrm{NaCl}, 5$ TEA-Cl, $2.5 \mathrm{Mg}_{2} \mathrm{ATP}$, and $0.25 \mathrm{Mg}_{2} \mathrm{GTP}$, pH 7.2-7.4, 275-285 mOsm. Picrotoxin $(100 \mu \mathrm{M})$ was added to the ACSF for recording, to block $\mathrm{GABA}_{\mathrm{A}}$ receptor-mediated IPSCs. Experiments were begun only after series resistance had stabilized (typically 15-40 M $\Omega$ ). Series and input resistance were monitored continuously on-line with a 5 $\mathrm{mV}$ depolarizing step $(25 \mathrm{msec})$. Data were filtered at $2 \mathrm{kHz}$, digitized at $10 \mathrm{kHz}$, and collected on-line with acquisition software (pClamp 8.2; Axon Instruments). DA neurons from the anterior VTA were identified by the presence of a large $I_{\mathrm{h}}$ current (Johnson and North, 1992) that was assayed immediately after break-in, using a series of incremental $10 \mathrm{mV}$ hyperpolarizing steps from a holding potential of $-70 \mathrm{mV}$. A bipolar stainless steel stimulating electrode (FHC) was placed $100 \mu \mathrm{m}$ rostral to the recording electrode and was used to stimulate at a frequency of $0.1 \mathrm{~Hz}$.

NMDA-mediated EPSCs were recorded at $+40 \mathrm{mV}$ and measured 20 msec after the stimulation artifact when the EPSC is primarily NMDAmediated (Bonci and Malenka, 1999; Ungless et al., 2001; Grillner and Mercuri, 2002; Ungless et al., 2003). AMPA-mediated EPSCs were recorded at $-70 \mathrm{mV}$. The amplitudes of AMPA EPSCs were calculated by taking a $1 \mathrm{msec}$ window around the peak of the EPSC and comparing this with the $5 \mathrm{msec}$ window immediately before the stimulation artifact. Paired stimuli were given with an interstimulus interval of $50 \mathrm{msec}$, and the ratio between the second and the first EPSCs was calculated and averaged for a $5 \mathrm{~min}$ baseline. The depolarizing pulse used to evoke depolarization-induced suppression of excitation (DSE) was a $500 \mathrm{msec}$ to $10 \mathrm{sec}$ step to $+40 \mathrm{mV}$ from holding potential $(-70 \mathrm{mV})$. The magnitude of DSE was measured as percentage of the mean amplitude of consecutive EPSCs after depolarization (acquired between 5 and $15 \mathrm{sec}$ after the end of the pulse) relative to that of five EPSCs before the depolarization (Ohno-Shosaku et al., 2002a). The spontaneous miniature EPSCs (mEPSCs) were collected in the presence of lidocaine $(500 \mu \mathrm{M})$ and analyzed (120 sweeps for each condition, $1 \mathrm{sec} / \mathrm{sweep}$ ) using Mini Analysis program (Synaptosoft, Decatur, GA). To accurately determine the mEPSC amplitude, only mEPSCs that were $>8 \mathrm{pA}$ were accepted for analysis (rise time $<1 \mathrm{msec}$, decay time $<3 \mathrm{msec}$ ). The choice of this cutoff amplitude for acceptance of mEPSCs was made to obtain a high signal-to-noise ratio. Then, each event was also visually inspected to prevent noise disturbance of the analysis. The cumulative amplitude and interevent plots obtained for each cell in control and after WIN application were compared using the Kolmogorov-Smirnov (KS) test. All the numerical data are given as mean \pm SEM and compared using the Student's $t$ test. Each slice received only a single drug exposure. Drugs were applied in known concentrations to the superfusion medium. WIN55,212-2, AM281, AM404, capsazepine, capsaicin, and quinpirole were purchased from Tocris Cookson (Bristol, UK). Other chemicals were purchased from Sigma (Milan, Italy). SR141716A was a generous gift from Sanofi research (Montpellier, France). All the drugs were dissolved in DMSO. The final concentration of DMSO was $<0.01 \%$.

Averaged data from different experiments are presented as mean \pm SEM. Statistical significance was assessed using one- or two-way ANOVA for repeated measures followed either by Dunnett's or $t$ test, where appropriate.

\section{Results}

The synthetic CB1-R agonist WIN inhibits excitatory synaptic transmission through a presynaptic mechanism

In the present study we first investigated whether or not CB1-R activation might affect excitatory synaptic transmission onto VTA DA cells. Single VTA DA neurons in midbrain hemislices were recorded in the whole-cell configuration. We first measured EPSCs recorded from DA neurons in rat midbrain slices at a time point when the EPSC is purely NMDA-mediated (see Materials and Methods), while holding the neurons in voltage-clamp at $+40 \mathrm{mV}$. Bath application of the synthetic CB1-R agonist WIN, at a concentration of $1 \mu \mathrm{M}(5 \mathrm{~min})$, significantly reduced NMDA EPSCs (by $50 \pm 15 \%, n=6$; one-way ANOVA plus Dunnett's test, $F_{(19,100)}=3.618 ; p<0.0001$ ) (Fig. $1 A, B$ ). The effect of WIN was not reversible on washout for $10 \mathrm{~min}$, probably because this highly lipophilic drug is not readily washed out from the brain slice. Indeed, most likely because of the strong lipophilicity of cannabinoid drugs their effects in brain slices are usually not reversible (Szabo et al., 1998, 2002; Ameri et al., 1999; Auclair et al., 2000; Vaughan et al., 2000; Huang et al., 2002). Therefore, no further attempts were made to wash out the effects of WIN.

The reduction of NMDA EPSCs amplitude observed could be explained by either a presynaptic effect on glutamate release, a postsynaptic change of the NMDA receptors, or a combination of these. We, therefore, decided to bath apply WIN and measure AMPA-mediated EPSCs while holding the cells at $-70 \mathrm{mV}$. As shown in Figure $1 C$, WIN caused a significant decrease of AMPA EPSCs (by $60 \pm 8 \%, n=7$; one-way ANOVA plus Dunnett's test $\left.F_{(19,120)}=26.204 ; p<0.0001\right)$, and increased the paired-pulse ratio (from EPSC2/EPSC1 $=1.07 \pm 0.2$ to EPSC2/EPSC1 $=$ $2.06 \pm 0.5$ before and after WIN, respectively; $n=7 ; t$ test, $t=$ $4.86, p<0.0005$ ) (Fig. $1 D)$. Because changes in transmitter release have been reported to generally affect the paired-pulse ratio in several brain regions (Mennerick and Zorumski, 1995; Debanne et al., 1996; Salin et al., 1996), including the VTA (Bonci 

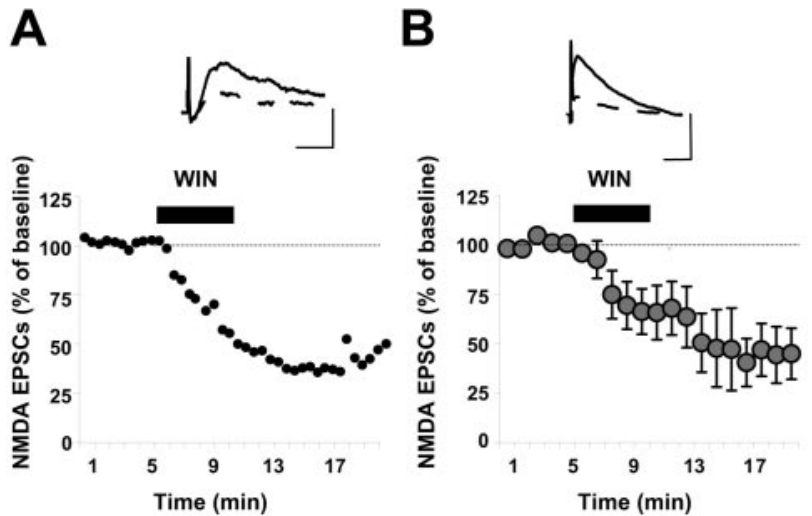

C
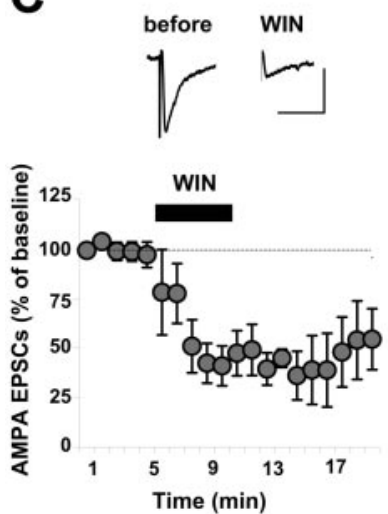

D
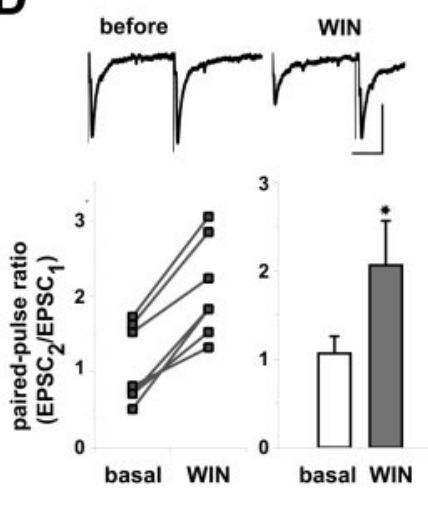

Figure 1. WIN induces inhibition of glutamatergic synaptic transmission in rat anterior VTA $D A$ cell. $A$, A typical whole-cell patch clamp recording showing that bath application of the CB-R agonist WIN 55, 212-2 (WIN; $1 \mu \mathrm{m})$ inhibits NMDA EPSCs amplitude $(n=6 ; p<0.0001)$ when cells are held at $+40 \mathrm{mV}$. Representative traces are shown in the inset. The inset shows single NMDA EPSC from a typical experiment, before (black line) and during (dashed line) superfusion of WIN. Calibration: 100 pA, $10 \mathrm{msec}$. $B$, WIN reduces NMDA EPSCs amplitude $(n=6 ; p<$ 0.0001 ), when cells are held at $+40 \mathrm{mV}$. All data are normalized to the respective baseline (5 min of baseline). Black bars show time of superfusion of WIN. SEM bars are smaller than symbols in some cases. The inset shows 10-trace averages of NMDA EPSCs before (black line) and during (dashed line) application of WIN. Calibration: 100 pA, 20 msec. C, WIN reduces AMPA EPSC amplitude ( $n=7 ; p<0.0001$ ) when cells are held at $-70 \mathrm{mV}$. All data are normalized to the respective baseline ( $5 \mathrm{~min}$ of baseline). Black bars show time of superfusion of WIN. SEM bars are smaller than symbols in some cases. Representative traces of AMPA EPSCs before and during application of WIN are shown in the inset. Calibration: 100 pA, 20 msec. D, WIN enhances the paired-pulse ratio of AMPAEPSCs (from EPSC2/EPSC1 $=1.07 \pm 0.2$ to EPSC2/EPSC $1=2.06 \pm$ $0.5 ; n=7 ; p<0.0005)$. The left-hand graph plots the paired-pulse ratio for each of the experiments in ( before (basal) and after (WIN) the application of WIN, whereas the right-hand graph plots the averaged paired-pulse ratio in a bar graph form. Representative traces are shown in the inset. Calibration: 100 pA, 20 msec.

and Williams, 1997; Manzoni and Williams, 1999; Melis et al., 2002), these results suggest that WIN might reduce glutamate release at a presynaptic site. To further test this possibility, we examined spontaneous AMPA mEPSCs. Figure $2, A$ and $B$, shows that the frequency of mEPSCs was significantly reduced after bath application of WIN (basal: $1.19 \pm 0.3 \mathrm{~Hz} ; n=5$; WIN: $0.4 \pm 0.1$ Hz; $n=5 ; t$ test, $t=5.58 ; p<0.001$ ) without affecting their amplitude, with mean amplitudes of $15.86 \pm 1.1$ and $14.99 \pm$ $0.88 \mathrm{pA}$ before and after WIN application, respectively (Fig. $2 A, C)(t$ test, $t=1.43 ; p>0.1)$. A decreased frequency but not amplitude of mEPSCs is generally thought to reflect a presynaptic decrease in probability of transmitter release (Katz, 1971). Therefore, these results indicate that WIN inhibits both NMDA and AMPA EPSCs by reducing the probability of glutamate release from the presynaptic terminals.
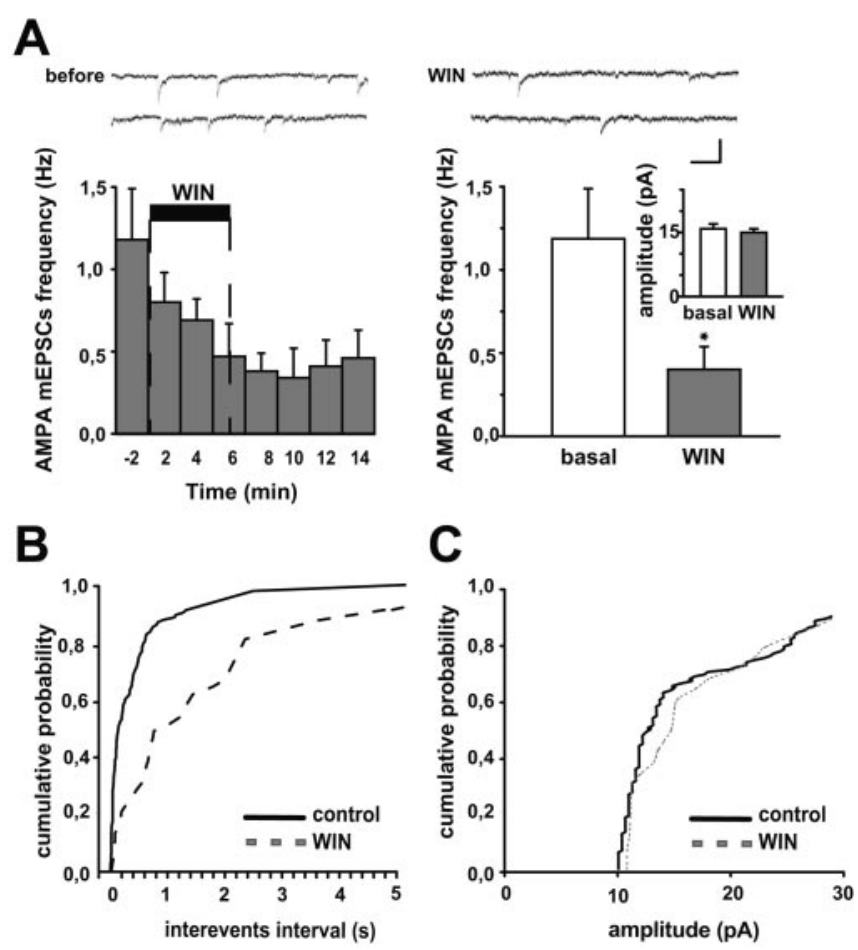

Figure 2. WIN reduces mEPSCs frequency without affecting the amplitude. $A$, Representative consecutive $1 \mathrm{sec}$ sweeps from a cell in which mEPSCs were recorded before (left) and after 5 min of application of WIN (right) are shown in the top panel. The running average histogram of mEPSC frequency showing the time course of the decrease produced by WIN (left), and the summary graph histogram (right) of the effect induced by WIN on mEPSCs frequency (from $1.19 \pm 0.3-0.4 \pm 0.1 \mathrm{~Hz} ; n=5 ; p<0.001$ ) and amplitude (basal: $15.86 \pm 1.1 \mathrm{pA} ;$ WIN: $14.99 \pm 0.88 \mathrm{pA}$ ) are shown in the bottom panel. Calibration: $20 \mathrm{pA}, 150 \mathrm{msec}$. $B$, Cumulative distribution plot of mEPSC interevent intervals of a single neuron (154 events) shows a decreased frequency after 5 min of superfusion with WIN (dashed line, 40 events) compared with the baseline (black line). C, On the contrary, mEPSC amplitude distribution was unchanged (dashed line) when compared with the baseline (black line).

\section{CB1-Rs mediate WIN-induced effect on glutamatergic synaptic transmission}

The decrease of both NMDA and AMPA EPSCs produced by WIN was concentration-dependent over the concentration range $100 \mathrm{~nm}$ to $3 \mu \mathrm{M}$ (Fig. $3 A)(n=5-7)$. In addition, its effect was mimicked by the structurally dissimilar CB1-R agonist HU210 (100 nM to $3 \mu \mathrm{M}, n=5$; NMDA EPSCs: one-way ANOVA, $F_{(2,9)}=255.21, p<0.0001$; AMPA EPSCs: one-way ANOVA, $F_{(2,12)}=273.78, p<0.0001$ ) (Fig. $3 B$ ). The statistical analysis revealed that HU210 was more potent than WIN in reducing NMDA EPSCs (one-way ANOVA plus Bonferroni's test, $100 \mathrm{nm:}$ $p<0.01, t=3.06 ; 1 \mu \mathrm{M}: p<0.05, t=2.57 ; 1 \mu \mathrm{M}: p<0.001, t=$ 4.65), whereas no difference between the two CB1-R agonists was found on AMPA EPSCs. These observations raised the possibility that the decrease in glutamatergic transmission could be due to activation of CB1-Rs.

Next, we tested the antagonist AM281, whose potency and selectivity for CB1-R has been demonstrated (Gatley et al., 1998). Coapplication of AM281 (500 nM) with WIN $(1 \mu \mathrm{M})$ abolished WIN-induced inhibition of both NMDA and AMPA EPSCs $(n=$ 5 for each experimental group, two-way ANOVA, $F_{(1,40)}=14.75$; $p=0.0004$ ) (Fig. 3C,E). We then tested the effect of another CB1-R antagonist, SR141716A, at a concentration of $1 \mu \mathrm{M}(5$ min). This low concentration was chosen because previous reports have shown that this drug can act as an inhibitor of vanilloid receptor (VR1)-mediated signaling at higher $(>2.5 \mu \mathrm{M})$ concen- 


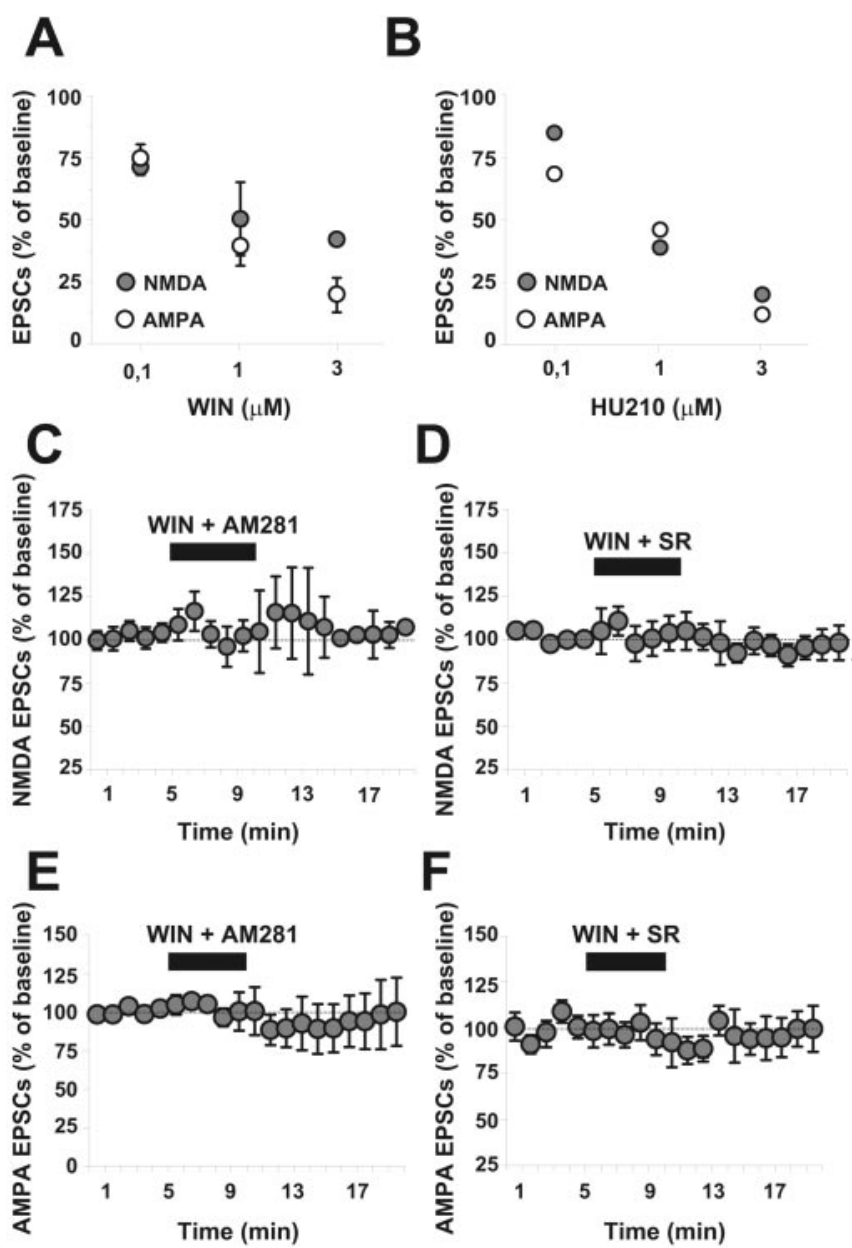

Figure 3. Cannabinoid-induced inhibition of glutamatergic synaptic transmission involves activation of CB1-Rs. A, Concentration-response relationship for percentage decrease in AMPA (open circles) and NMDA (closed circles) EPSCs size produced by WIN (0.1-3 $\mu \mathrm{M}$ ). Each point shows the mean \pm SEM of responses of different neurons $(n=5-7)$. B, Concentrationresponse relationship for percentage decrease in AMPA (open circles) and NMDA (closed circles) EPSCs amplitude produced by HU210 (0.1-3 $\mu \mathrm{M})$. Each point shows the mean \pm SEM of responses of different neurons $(n=5)$. C, Coapplication of WIN with the selective CB1-R antagonist AM281 (500 nM) abolishes WIN-induced effect on NMDA EPSCs $(n=5 ; p<0.001)$. $D$, Coapplication of WIN with the CB1-R antagonist SR141716A (SR; $1 \mu \mathrm{m}$ ) readily blocked the WIN-induced inhibition of NMDA EPSCS $(n=8 ; p=0.001)$. E, Coapplication of WIN with the selective CB1-R antagonist AM281 (500 nM) abolishes WIN-induced effect on AMPA EPSCs $(n=$ $5 ; p<0.001) . F$, Coapplication of WIN with the CB1-R antagonistSR141716A (SR; $1 \mu \mathrm{M}$ ) readily prevented the WIN-induced inhibition of AMPA EPSCS $(n=5 ; p=0.001)$. All data are normalized to the respective baseline ( 5 min of baseline). Black bars show the time of superfusion of the drugs.

trations (White and Hiley, 1998; Chaytor et al., 1999; Zygmunt et al., 1999; De Petrocellis et al., 2001). SR141716A readily antagonized the inhibition of both NMDA and AMPA EPSCs induced by WIN $\left(n=8\right.$; two-way ANOVA, $\left.F_{(1,40)}=11.54 ; p=0.001\right)$ (Fig. $3 D, F)$. Taken altogether, these results indicate that activation of CB1-Rs is responsible for WIN-induced effects on glutamatergic transmission in the VTA.

\section{Endocannabinoids modulate excitatory synaptic transmission}

Interestingly, both AM281 (500 nM) and SR141716A ( $1 \mu \mathrm{M})$ per se significantly increased NMDA EPSCs (Fig. 4A,B). In fact, AM281 increased NMDA EPSCs by $42 \pm 7 \%$ above basal (oneway ANOVA plus Dunnett's, $F_{(19,100)}=19.583 ; p<0.005 ; n=6$ )
(Fig. 4A), and SR141716A produced an increment of $35 \pm 10 \%$ above basal (one-way ANOVA plus Dunnett's, $F_{(19,140)}=19.583$; $p<0.0001 ; n=8$ ) (Fig. $4 B$ ). These data suggest that there is a tonic activation of CB1-R that is blocked by the antagonists. In fact, our observation that neither AM281 nor SR141716A per se affected AMPA EPSCs (data not shown) raised the possibility that when DA cells are depolarized (by holding them at $+40 \mathrm{mV}$ ) CB1-Rs might be tonically active. Eventually, this phenomenon could be ascribed to endocannabinoids produced and released from depolarized postsynaptic DA neurons, as described in other brain regions (Kreitzer and Regehr, 2001; Maejima et al., 2001; Ohno-Shosaku et al., 2001; Wilson and Nicoll, 2001; Wilson et al., 2001; Kreitzer et al., 2002; Ohno-Shosaku et al., 2002b; Brenowitz and Regehr, 2003; Brown et al., 2003). Because the synthesis of endocannabinoids is normally balanced by a fast uptake, which keeps their extracellular levels below those required for CB1-R activation (Beltramo et al., 1997; Piomelli et al., 1999), we decided to test our hypothesis using AM404, an endocannabinoid reuptake inhibitor, to allow them to reach sufficient concentrations in the slice. Because AM404 also acts as a VR1 agonist (Smart and Jerman, 2000), we coapplied AM404 (10 $\mu \mathrm{M})$ with the selective VR1 antagonist capsazepine (CPZ; $10 \mu \mathrm{M})$. As shown in Figure $4 C, \mathrm{CPZ}(10 \mu \mathrm{M}, 5 \mathrm{~min})$ produced a significant decrease of NMDA EPSCs on its own (by $35 \pm 16 \%, n=5$; one-way ANOVA plus Dunnett's, $\left.F_{(19,80)}=3.11 ; p=0.0002\right)$, thus supporting the previously reported existence of an endogenous vanilloid tone within the VTA (Marinelli et al., 2003). Nevertheless, coapplication of AM404 with CPZ further decreased NMDA EPSCs (up to $70 \pm 5.2 \%$ of baseline, $n=5$; two-way ANOVA; $F_{(1,40)}=14.44$; $p=0.0005$ ) (Fig. 4C), thus strengthening the hypothesis that endocannabinoids might be produced and released during depolarization of DA cells, and act retrogradely onto presynaptic $\mathrm{CB} 1-\mathrm{Rs}$ to reduce glutamate release. If that is the case, then one would expect that direct application of an endocannabinoid could produce depression of glutamatergic transmission. To test this possibility, we examined the effects of R1-methanandamide (mAEA), the synthetic analog of anandamide that has higher stability to amidase activity (Romero et al., 1996). Unexpectedly, mAEA $(2 \mu \mathrm{M}, 5 \mathrm{~min})$ did not significantly affect the NMDA EPSCs amplitude $(n=5$; one-way ANOVA, $p>0.1)$ (Fig. $4 D)$. However, several investigators have provided evidence that anandamide, at concentrations similar or higher than those required to activate CB1-Rs, also functions as an agonist at VR1 (Zygmunt et al., 1999; Maccarrone et al., 2000; Smart et al., 2000; Ross et al., 2001). Therefore, to isolate the CB1-R mediated effects of mAEA, we decided to antagonize the VR1-mediated. Not surprisingly, when mAEA was coapplied with CPZ $(10 \mu \mathrm{M})$ the NMDA EPSCs amplitude decreased up to $32 \pm 0.4 \%$ of baseline ( $n=5$; two-way ANOVA, $F_{(19.40)}=16.65 ; p=0.0002$ ) (Fig. $4 E$ ). This latter result, together with the effect produced by VR1 antagonist $\mathrm{CPZ}$ on its own (Fig. 4C), is consistent with an increased glutamatergic transmission mediated by activation of VR1 in the midbrain (Marinelli et al., 2003). In fact, superfusion of the selective VR1 agonist capsaicin (CPS; $1 \mu \mathrm{M}$ for $5 \mathrm{~min}$ ) induced a robust increase of NMDA EPSCs (by $92 \pm 27 \%, n=5$; one-way ANOVA plus Dunnett's, $\left.F_{(19,80)}=13.857 ; p<0.0001\right)$ (Fig. $\left.4 F\right)$, that was prevented by coapplication of CPZ $(10 \mu \mathrm{M} ; n=5$; two-way ANOVA, $\left.F_{(1.40)}=21.32 ; p<0.0001\right)($ Fig. $4 F)$.

Taken altogether, these results suggest that endocannabinoids, produced and released during depolarization, retrogradely diffuse toward the presynaptic terminal where they would modulate glutamate release, through activation of either CB1-R or VR1. 
A
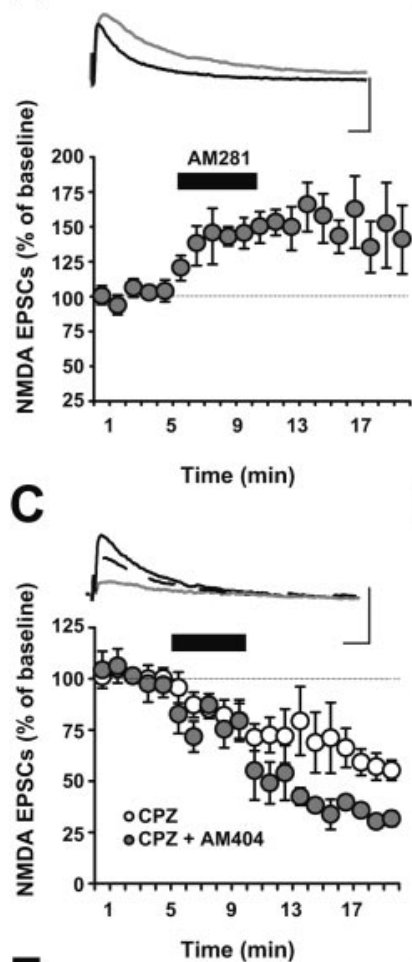

E

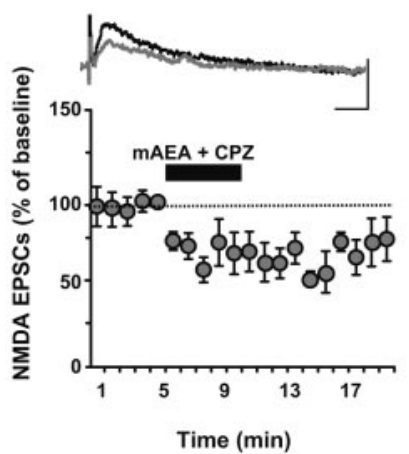

B

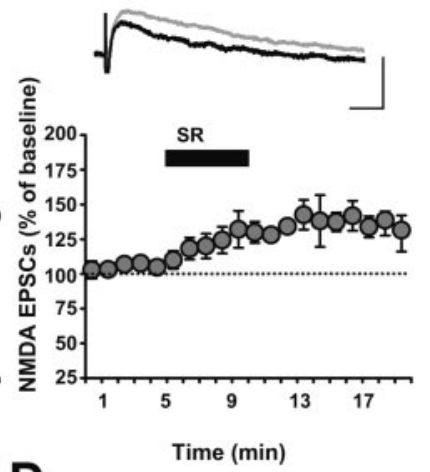

D

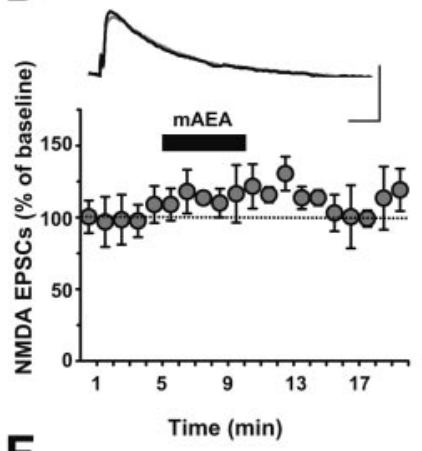

$\mathbf{F}$

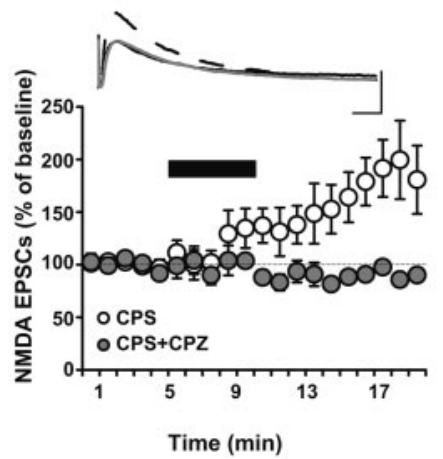

Figure 4. Endocannabinoids modulate excitatory synaptic transmission in rat anterior VTA. A, Superfusion of AM281 (500 nM) by itself produces a significant increase of NMDA EPSCs ( $n=$ $6 ; p<0.005$ ). All data are normalized to the respective baseline ( 5 min of baseline). Black bars show the time of superfusion of the drug. The inset shows 10-trace averages of NMDA EPSCS before (black line) and during application of AM281 (gray line). Calibration: 100 pA, 20 msec. B, Bath application of SR $(1 \mu \mathrm{M})$ per se significantly increased NMDA EPSCs $(n=8 ; p<0.0001)$. All data are normalized to the respective baseline ( 5 min of baseline). Black bars show the time of superfusion of the drug. SEM bars are smaller than symbols in some cases. The inset shows representative traces of NMDA EPSCs before (black line) and during application of SR (gray line). Calibration: 100 pA, 20 msec. C, Bath application of the selective VR1 antagonist capsazepine (CPZ; $10 \mu \mathrm{m}$, open circles) produced a significant decrease of NMDA EPSCs on its own $(n=5$; $p=0.0002$ ). Coapplication (closed circles) of the endocannabinoid reuptake inhibitor AM404 $(10 \mu \mathrm{M})$ with CPZ further decreased NMDA EPSCs $(n=5 ; p=0.0005)$. All data are normalized to the respective baseline ( $5 \mathrm{~min}$ of baseline). Black bars show the time of superfusion of the drugs. The inset shows 10 -trace averages of NMDA EPSCs before (black line) and during application of CPZ (dashed line) and CPZ with AM404 (gray line). Calibration: 100 pA, 20 msec. D, Superfusion of methanandamide (mAEA; $2 \mu \mathrm{m})$ did not significantly affect $\operatorname{NMDA} \operatorname{EPSCs}(n=5$; $p>0.05$ ). All data are normalized to the respective baseline ( $5 \mathrm{~min}$ of baseline). Black bars show the time of superfusion of the drug. The inset shows 10-trace averages of NMDA EPSCS before (black line) and during application of mAEA (gray line). Calibration: 100 pA, 20 msec. $E$, Coapplication of mAEA $(2 \mu \mathrm{M})$ with CPZ $(10 \mu \mathrm{M})$ significantly decreased NMDA EPSCs $(n=5$; $p<0.0002$ ). All data are normalized to the respective baseline ( $5 \mathrm{~min}$ of baseline). Black bars show the time of superfusion of the drugs. SEM bars are smaller than symbols in some cases. The inset shows representative traces of NMDA EPSCs before (black line) and during application of

Endocannabinoids mediate suppression of excitatory synaptic transmission

Endocannabinoids have been reported to account for a type of modulation, termed depolarization-induced suppression of excitation (DSE), in other brain regions (Kreitzer and Regehr, 2001; Maejima et al., 2001; Kreitzer et al., 2002; Ohno-Shosaku et al., 2002b; Brenowitz and Regehr, 2003; Brown et al., 2003). DSE is a transient reduction in presynaptic glutamate release after postsynaptic depolarization that reduces neuronal excitability by allowing the target neurons to regulate the strength of afferent excitation. Therefore, we then examined whether depolarization of the postsynaptic neuron could induce DSE in rat anterior VTA.

The DA neuron was depolarized for $10 \mathrm{sec}$ from -70 to +40 $\mathrm{mV}$ under voltage-clamp mode. The subsequent EPSCs were transiently suppressed, indicating that the depolarizing step effectively induced DSE ( $28.6 \pm 6 \%$ of basal, $n=5$; $t$ test, $t=24.57$; $p<0.0001$ ) (Fig. 5A,B). Furthermore, the increased paired-pulse ratio occurred during DSE (from EPSC2/EPSC1 $=1.1 \pm 0.2$ to EPSC2/EPSC1 $=1.7 \pm 0.2$ before and after DSE, respectively; $n=5 ; t$ test, $t=2.12 ; p<0.05$ ) (Fig. $5 C$ ) is consistent with a decreased probability of transmitter release. Subsequently, we examined whether DSE was mediated by an endocannabinoid. Pretreatment of slices with either AM281 (500 nM) or SR141716A $(1 \mu \mathrm{M})$ blocked DSE in the VTA, because in their presence the depolarizing voltage pulse (from -70 to $+40 \mathrm{mV} ; 10 \mathrm{sec}$ ) caused no significant suppression of EPSCs (being 107.3 \pm 9 and $84.7 \pm$ $8 \%$ of baseline in the presence of AM281 and SR141716A respectively; $n=5$ for each condition; $t$ test, $t=16.019 ; p<0.0001$ ) (Figs. $5 D, 6 C$ ). In addition, activation of CB1-Rs by pretreating the slices with WIN ( $1 \mu \mathrm{M}, 5 \mathrm{~min})$ occluded DSE, being the EPSCs amplitude after the depolarizing pulse $114.7 \pm 15 \%$ of baseline $(n=5 ; t$ test, $t=5.678 ; p=0.0005)$ (Figs. $5 E, 6 C)$. These results indicate that also in the VTA DSE is mediated by endocannabinoids released from depolarized postsynaptic neurons and suppresses the excitatory synaptic transmission mainly through activation of CB1-Rs. These findings are also supported by the strong correlation between the magnitudes of AM404-induced inhibition and DSE when data are fit by linear regression $\left(r^{2}=\right.$ $0.98 ; n=5$ ) (Fig. $5 F$ ). Therefore, the most likely explanation for the observed DSE appears to be that depolarization of DA cells affected presynaptic function via retrograde signaling.

\section{DSE in VTA DA neurons}

DSE has been previously shown to be sensitive to the duration of depolarization (Ohno-Shosaku et al., 2002b). We, therefore, examined DSE induced by voltage steps of varying durations $(0.5,1$, 3 , and 5 sec; $n=7$ per each pulse) (Fig. $6 A, B$ ). As shown in Figure $6, A$ and $B$, a 5 sec depolarization induced significant DSE (EPSCs amplitude after the depolarizing pulse was $73.8 \pm 6 \%$ of baseline; $n=6$; $t$ test, $t=4.14 ; p=0.001$ ), whereas depolarization of shorter duration did not. Subsequently, to investigate the role of postsynaptic $\mathrm{Ca}^{2+}$ in triggering the release of endocannabinoids, we loaded DA cells with the membrane permeant $\mathrm{Ca}^{2+}$ chelator BAPTA (15 mM). Under these conditions, in eight of nine cells

$\leftarrow$

mAEA with CPZ (gray line). Calibration: 100 pA, 20 msec. F, The VR1 agonist capsaicin (CPS; 1 $\mu \mathrm{M}$, open circles) induces a robust increase of NMDA EPSCS $(n=5 ; p<0.0001)$, that was prevented by coapplication of CPZ (10 $\mu \mathrm{m} ; n=5 ; p<0.0001$; closed circles). All data are normalized to the respective baseline ( $5 \mathrm{~min}$ of baseline). Black bars show the time of superfusion of the drugs. SEM bars are smaller than symbols in some cases. The inset shows representative traces of NMDA EPSCs before (black line) and during application of CPS (dashed line) and (PS with CPZ (gray line). Calibration: 100 pA, 20 msec. 
A
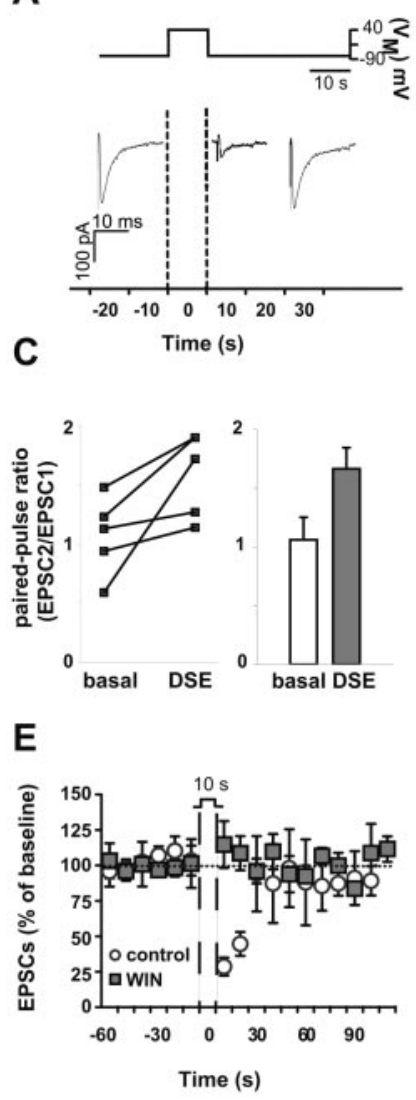

B
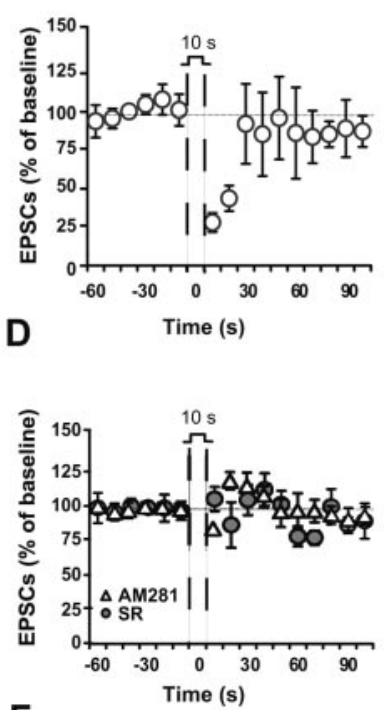

$\mathbf{F}$

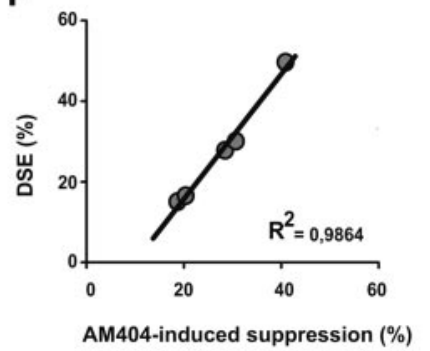

A

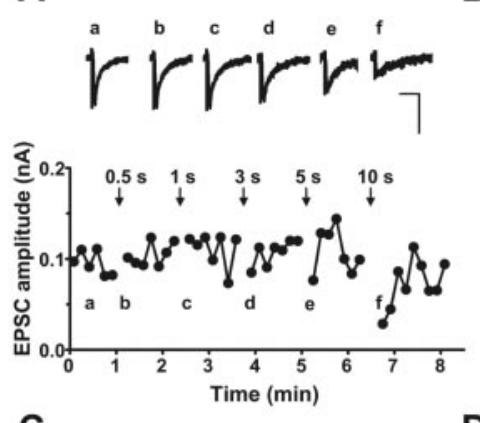

C

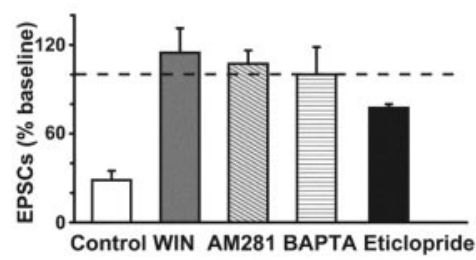

B

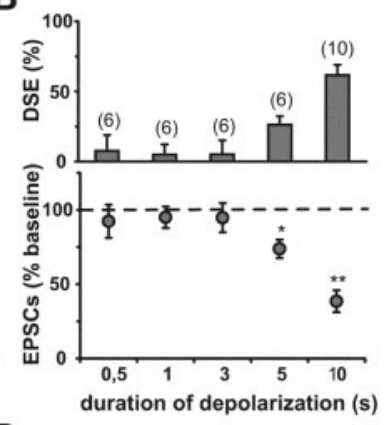

Figure 6. DSE in VTA DA neurons is a presynaptic phenomenon mediated by a postsynaptic excitation. $A$, Induction of DSE depends on duration of depolarization. Example of DSE by various depolarizing pulses with durations of $0.5-10 \mathrm{sec}$. The postsynaptic neuron was depolarized at the times indicated by arrows. Representative traces of EPSCs acquired at the indicated points are shown in the inset. Calibration: $10 \mathrm{msec}, 100 \mathrm{pA}$. B, Averaged data for DSE induced by depolarizing pulses with a duration of $0.5,1,3,5$, and 10 sec are plotted in the top panel. The relationship between the depolarizing pulse duration and the relative amplitude of EPSCS obtained after $5-15$ sec after the end of depolarization is plotted in the bottom panel. The amplitude was normalized to the averaged value (dotted line) before depolarization. Each symbol represents the averaged value obtained from different cells $\left(n=6-10 ;{ }^{*} p=0.001 ;{ }^{* *} p<\right.$ $0.0001)$. C, DSE in the VTA requires endocannabinoids and $\mathrm{Ca}^{2+}$, as well as DA. AM281 blocks DSE by antagonism, and WIN by occlusion. DSE is abolished by filling cells with BAPTA (15 mM), and partially blocked by the $D_{2} D A$ antagonist eticlopride. Magnitude of EPSCS amplitude after the depolarizing pulse for all conditions plotted as the percentage of baseline before the pulse (control, $n=5$; WIN, $n=5 ;$ AM281, $n=5 ;$ BAPTA; $n=9$, Eticlopride, $n=7$ ). D, Effect of eticlopride on DSE. The graph plots individual data obtained before (control) and during application of eticlopride. DSE was induced by 10 sec depolarization. is the aver of the man ES of the mean EPSCs for the 10 sec period from five different cells. increases paired-pulse ratio of AMPA EPSCS $(n=5 ; p<0.05)$. The left-hand graph plots the paired-pulse ratio for each of the experiments in B before (basal) and $5-15$ sec after (DSE) the depolarizing step, whereas the right-hand graph plots the averaged paired-pulse ratio in a bar graph form. $D$, In the presence of either AM281 (500 nм, open triangles) or SR (1 $\mu \mathrm{M}$, closed circles) the depolarizing voltage pulse caused no changes of EPSCs size ( $n=5$ for each condition; $p<0.0001)$. The VTA DA neurons were depolarized from -70 to $+40 \mathrm{mV}$ for $10 \mathrm{sec}$ under voltage-clamp mode. Each point is the average of the mean EPSCs for the 10 sec period from five different cells for each condition. $E$, Time course of the transient suppression of EPSCS induced by depolarization of VTA DA neuron ( $n=5 ; p<0.0001$; open circles) and occlusion of DSE induced by WIN ( $n=5 ; p=0.0005$; closed squares). In the presence of WIN ( $1 \mu \mathrm{m}$; closed squares) the depolarizing voltage pulse caused no changes of $\operatorname{EPSC}(n=5 ; p=0.0005)$. The VTA DA neurons were depolarized from -70 to $+40 \mathrm{mV}$ for 10 sec under voltage-clamp mode. Each point is the average of the mean EPSCs for the 10 sec period from five different cells for each condition. $F$, The magnitude of EPSCs inhibition induced by DSE is plotted as a function of the inhibition induced by AM 404 for the five cells in $B$ and Figure $3 C$, respectively. The data are fit by linear regression with $r^{2}=0.98(p<0.001)$.

the DSE was abolished (being $100.1 \pm 18 \%$ of baseline, $n=9 ; t$ test, $t=2.835 ; p<0.001$ ) (Fig. $6 C$ ), strongly suggesting that the induction of DSE requires a postsynaptic rise in intracellular $\mathrm{Ca}^{2+}$. Endocannabinoid signaling has been shown to be facilitated by classical neurotransmitters in different brain regions (Maejima et al., 2001; Varma et al., 2001; Ohno-Shosaku et al., 2002a, 2003). Because dendrites of VTA DA cells release DA in an activity dependent manner (Rice et al., 1997; Jaffe et al., 1998), which activates $\mathrm{D}_{2} \mathrm{DA}$ autoreceptors, we tested DSE sensitivity to

the $\mathrm{D}_{2} \mathrm{DA}$ antagonist eticlopride $(100 \mathrm{~nm})$. As shown in Figure 6, $C$ and $D$, DSE was significantly suppressed by eticlopride (being $77.5 \pm 5.2 \%$ of baseline, $n=9$; $t$ test, $t=3.936 ; p=0.0013$ ), suggesting a modulatory function of DA in DSE. Furthermore, application of the $\mathrm{D}_{2} \mathrm{DA}$ agonist quinpirole $(0.1-1 \mu \mathrm{M})$ did not affect EPSCs $(n=5)$ (Fig. $7 A$; see also Thomas et al., 2000 for a similar effect of quinpirole on AMPA EPSCs at $10 \mu \mathrm{M}$ ), but enhanced the 3 sec DSE in a dose-dependent manner $(n=5$ for each concentration; quinpirole $1 \mu \mathrm{M}$ vs $3 \mathrm{sec}$ DSE: $t=3.184, p=$ 0.012 ) (Fig. $7 A, B)$. The effect of $3 \mathrm{sec}$ depolarization in the presence of $0.3 \mu \mathrm{M}$ quinpirole was almost equivalent to that of $5 \mathrm{sec}$ depolarization without quinpirole $(n=5 ; t=0.011 ; p=0.99)$ (Fig. 7B). In addition, the CB1-R antagonist AM281 (500 nM) suppressed the $3 \mathrm{sec}$ DSE in the presence of $1 \mu \mathrm{M}$ quinpirole $(n=$ 7) (Fig. $7 A, B)$. In fact, DSE induced by a depolarizing pulse ( $3 \mathrm{sec}$ ) in the presence of both AM281 and quinpirole significantly differs from that induced in the presence of quinpirole alone $(t=$ $4.95 ; p=0.0006)$, but not from the control $(t=1.38 ; p=0.19)$, thus suggesting that activation of $\mathrm{D}_{2} \mathrm{DA}$ receptors might induce the release of endocannabinoids that act retrogradely onto CB1-Rs.

The enhancement of DSE could be attributable to either an increased sensitivity of presynaptic CB1-Rs or facilitation of endocannabinoids release from the postsynaptic neurons. To test 
A

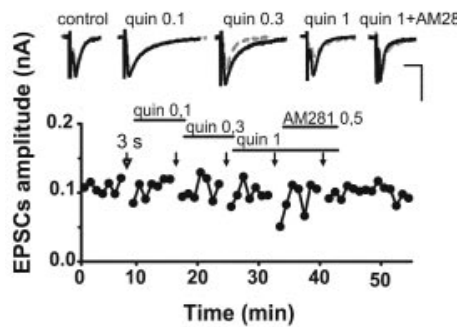

C

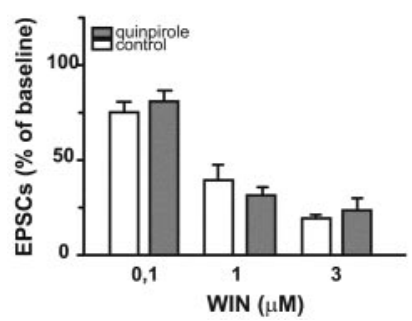

B

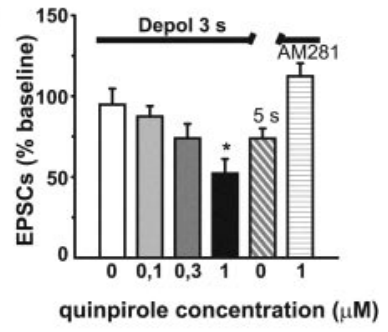

D

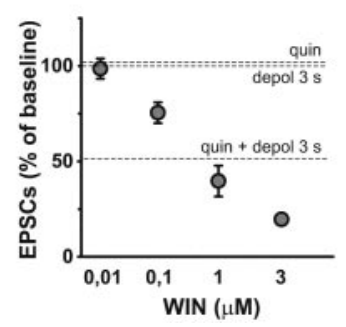

Figure 7. Facilitation of DSE by quinpirole. $A$, A representative experiment demonstrating a dose-dependent enhancement of DSE by quinpirole (quin). DSE was induced by 3 sec depolarization. EPSC traces acquired before (black line) and after depolarization (dashed line) have been superimposed for each DSE trial and are shown in the inset. Calibration: $10 \mathrm{msec}, 100 \mathrm{pA}$. $B$, Summary graph showing averaged data for the enhancement of DSE by quinpirole $(n=5)$ and blockade by the CB1-R antagonist AM281 ( $n=5 ; p=0.0006)$. Quinpirole concentrations are shown below the columns. DSE was induced by either 5 or $3 \mathrm{sec}$ (four columns on the left, and first one from the right) depolarization. The asterisk represents statistically significant difference from the control (3 sec depolarization, 0 quinpirole; ${ }^{*} p=0.001$ ). C, Dose-dependent suppression of EPSCs by WIN. The graph plots the effect of WIN on EPSC amplitude in absence (open columns) and presence (shaded) of $1 \mu \mathrm{m}$ quinpirole $(n=5)$. D, Relative amplitudes of EPSCs are plotted against the concentration of WIN. Each symbol represents the averaged value from different cells $(n=5-7)$. Horizontal dotted lines indicate the levels of suppression induced by $1 \mu$ m quinpirole, 3 sec depolarization, and $1 \mu$ m quinpirole +3 sec depolarization.

the former possibility, we examined whether quinpirole affected the sensitivity of EPSCs to WIN. Quinpirole $(1 \mu \mathrm{M})$ did not affect WIN-induced decrease of EPSCs $(0.1-3 \mu \mathrm{M} ; n=5 ; p>0.05)$ (Fig. $7 C$ ), indicating that quinpirole enhances DSE mainly by facilitating the release of endocannabinoids. Because our electrophysiological technique does not allow to measure the released endocannabinoids directly, we attempted to indirectly estimate the relative number of CB1-Rs activated by endocannabinoids before and during bath application of quinpirole as the equivalent amount of CB1-Rs activated by WIN (Ohno-Shosaku et al., 2002a, 2003). As shown in Figure 7D, the magnitudes of suppression of EPSCs induced by either quinpirole (quin, $1 \mu \mathrm{M}$ ) or DSE (depol, $3 \mathrm{sec}$ ) are estimated to be equivalent to those induced by $0.01 \mu \mathrm{M}$ WIN. In the presence of quinpirole, depolarization (quin plus depol $3 \mathrm{sec}$ ) further suppressed the EPSCs to $52.2 \%$ of baseline, and the estimated value is equivalent to $0.3 \mu \mathrm{M}$ WIN. If quinpirole and depolarization produce endocannabinoids through independent mechanisms, the number of CB1-Rs activated by endocannabinoids during depolarization plus quinpirole should be the algebraic sum of the estimated values for quinpirole and depolarization alone. However, the estimated value is $\sim 15$-times higher than the algebraic sum $(0.02 \mu \mathrm{M})$, indicating that activation of $\mathrm{D}_{2} \mathrm{DA}$ receptors significantly enhances the depolarization-induced release of endocannabinoids.

\section{Discussion}

The major finding of the present study is that depolarization of postsynaptic DA neurons within the VTA induces a $\mathrm{Ca}^{2+}$ -

dependent transient release of endocannabinoids that act retrogradely and inhibit glutamatergic release from the presynaptic terminals, and that the effect is dependent on activation of CB1Rs. We also provide evidence for the action of DA as a potent enhancer of endocannabinoid release from VTA DA cells. This enhancement would be ascribed to DA released from somatodendritic regions in an activity-dependent manner (when the postsynaptic cells are depolarized) and activating $\mathrm{D}_{2} \mathrm{DA}$ receptors located on the soma.

Several observations support our conclusion that DSE can be initiated postsynaptically by depolarization and expressed presynaptically as a suppression of glutamate release also in the VTA. First, cannabinoids and DSE both act on presynaptic targets. In fact, here we observe that WIN effects on both NMDA and AMPA EPSCs are entirely presynaptic. Moreover, these effects were indeed ascribed to CB1-R activation, because two CB1-R antagonists, SR141716A and the potent and selective AM281, blocked them. Additionally, WIN effects on both NMDA and AMPA EPSCs were dose-dependent and mimicked by another CB1-R agonist, HU210. The observation that HU210 was more potent than WIN on NMDA EPSCs, but not AMPA EPSCs, might suggest that discrete CB1-R subtypes can be activated during the different experimental conditions used to record NMDA and AMPA EPSCs. Nonetheless, a similar decrease in presynaptic glutamate release because of activation of CB1-Rs is in agreement with several other reports in different brain regions (Shen et al., 1996; Szabo et al., 2000; Gerdeman and Lovinger, 2001; Huang et al., 2001; Kreitzer and Regehr, 2001; Huang et al., 2002; OhnoShosaku et al., 2002b; Azad et al., 2003). Second, the maximum effect of DSE $(10 \mathrm{sec})$ and that of WIN $(1 \mu \mathrm{M})$ on EPSCs are quantitatively very close, being $61.4 \pm 7 \%$ and $60.6 \pm 8 \%$, respectively. Third, WIN occluded the DSE, suggesting a common target for both WIN and the endogenous retrograde signal. Fourth, the blockade of CB1-Rs with the two antagonists, AM281 and SR141716A, abolishes DSE, while having no effect on AMPA EPSCs. Fifth, the inhibitor of endocannabinoid reuptake AM404 inhibited EPSCs. Last, the strong correlation between the extents of the inhibition produced by AM404 and that produced by DSE (Fig. $5 F$ ) supports the possibility that most, if not all, of the AM404-sensitive excitatory afferents to DA neurons in the anterior VTA would be suppressed by depolarization.

The conclusion that endocannabinoids might account for DSE in the VTA is in agreement with their involvement in a similar form of transient inhibition of excitatory synaptic currents in the cerebellum (Kreitzer and Regehr, 2001, 2002; Brenowitz and Regehr, 2003; Brown et al., 2003) and the hippocampus (Ohno-Shosaku et al., 2002b; Chen et al., 2003). The question arises, however, of the compatibility with the traditional anatomical and immunohistochemical studies, which do not report CB1-Rs within the VTA (Herkenham et al., 1991; Matsuda et al., 1993). One possibility might be that since the receptor is likely to be presynaptic it could be synthesized in another brain region and transported to the presynaptic terminal in the VTA by axonal transport. In support with this hypothesis, CB1-R mRNA has been found in those brain regions that send glutamatergic afferents to the VTA, such as prefrontal cortex, subthalamic nucleus, pedunculopontine nucleus, and amygdala (Matsuda et al., 1993). On the other hand, the presence of endocannabinoids within the VTA would justify the colocalization of CB1-Rs and the DA neuronal marker, TH, recently reported (Wenger et al., 2003). Based on our experimental results we conclude that the CB1-R is the one activated by WIN, and responsible for DSE. Additionally, the observations that mAEA per se does not significantly affect 
NMDA EPSCs, and CPZ by itself inhibits NMDA EPSCs, indicate a tonic role of VR1 in facilitating, rather than inhibiting, excitatory transmission in the midbrain (Marinelli et al., 2003). Therefore, the resulting ineffectiveness shown by mAEA per se would support the idea that AEA, along with its role as endocannabinoid, might also function as an endovanilloid in the VTA as well. These data would argue against the possibility that AM404induced effects on NMDA ESPCs can be explained by its in vitro affinity for VR1. As a result, taken together with the notion that AM404 does not directly activate CB1-Rs in vitro (Beltramo et al., 1997; Beltramo and Piomelli, 2000), we tend to rule out the possibility that AM404 would activate VR1 rather than augment several other effects of endocannabinoids. Thus, a more plausible interpretation of the available data are that AM404, by inhibiting endocannabinoid clearance, might cause these lipids to accumulate outside cells and activate local CB1-Rs.

Previous studies reported that endocannabinoids are synthesized "on demand" in stimulated neurons and released, generally in a $\mathrm{Ca}^{2+}$-dependent manner (Di Marzo et al., 1998; Mechoulam et al., 1998; Piomelli et al., 2000). Consistently, we observed that DSE, in the VTA, is dependent on intracellular $\mathrm{Ca}^{2+}$, because it was completely abolished when BAPTA was perfused into the intracellular compartment. The role of postsynaptic $\mathrm{Ca}^{2+}$ in triggering the release of endocannabinoids is also in agreement with the induction of DSE in other brain regions (Kreitzer and Regehr, 2001; Maejima et al., 2001; Ohno-Shosaku et al., 2002b; Brenowitz and Regehr, 2003; Brown et al., 2003).

Other recent studies directly and indirectly support our findings and the presence of endocannabinoids within the VTA (Beltramo et al., 2000; Romero et al., 2002; Marinelli et al., 2003). Indeed, moderate immunoreactivity for the enzyme FAAH has been shown in the midbrain (Romero et al., 2002). In addition, relatively high levels of the endocannabinoid anandamide were found in this region (Di Marzo et al., 2000; Marinelli et al., 2003). Moreover, the effects of AM404 were also studied in juvenile spontaneously hypertensive rats (Beltramo et al., 2000), which are hyperactive and show a number of attention deficits linked to alterations in mesocorticolimbic DA transmission, as well as DA receptor expression. In these rats, inhibition of endocannabinoid reuptake alleviated certain symptoms of DA dysfunction (Beltramo et al., 2000), probably by inducing a phasic inhibition of mesocorticolimbic DA activity (A. G. Sadile, personal communication). Thus, an additional role for DSE might be to limit the synaptic drive onto VTA DA cells and prevent pathological overexcitation.

In agreement with a similar form of cooperation between depolarization and activation of postsynaptic mGluR1 (Maejima et al., 2001; Varma et al., 2001; Ohno-Shosaku et al., 2002a; Brown et al., 2003) or M1/M3 receptors (Ohno-Shosaku et al., 2003) in different brain regions, we here provided evidence for the role of somatodendritic DA as a potent enhancer of endocannabinoid signaling. In fact, once depolarized VTA DA neurons would release a large amount of endocannabinoids as a result of cooperative actions of intracellular $\mathrm{Ca}^{2+}$ and $\mathrm{D}_{2} \mathrm{DA}$ receptor activity. The resultant DSE would be larger than the DSE without $\mathrm{D}_{2} \mathrm{DA}$ receptor activation, and application of eticlopride decrease DSE, which appears as a partial blockade of DSE on first analysis. Our current hypothesis is that elevation of intracellular $\mathrm{Ca}^{2+}$ and activation of $\mathrm{D}_{2} \mathrm{DA}$ receptors could initiate a common intracellular cascade for endocannabinoid production. One possible candidate is the phospholipase C (PLC) signaling. In fact, micromolar concentrations of $\mathrm{Ca}^{2+}$ have been reported to potentiate PLC (Ryu et al., 1987) with a resultant production of IP3 (Okubo et al.,
2001), key in the production of 2AG (Stella et al., 1997). On the other hand, activation of $\mathrm{D}_{2} \mathrm{DA}$ receptors could lead to production of diacylglicerol (DAG) via PLC $\beta$ that is then converted to 2AG by DAG lipase (Stella et al., 1997). The present results lead us to speculate that PLC would be activated in a cooperative manner by $\mathrm{D}_{2} \mathrm{DA}$ receptor activation and depolarization-induced elevation of intracellular $\mathrm{Ca}^{2+}$, and that $2 \mathrm{AG}$ would mainly mediate DSE in the anterior VTA. However, at this stage we cannot rule out a contribution by anandamide, because of the high levels found in this region (Marinelli et al., 2003). Independently of the underlying mechanisms, this is the first evidence, to our knowledge, that DA acts as a modulator of DSE. However, we cannot exclude that endocannabinoid production could be facilitated by activation of other postsynaptic Gq/II receptors, such as I mGluRs or M3/M5 receptors.

The physiological significance of endocannabinoids signaling in the anterior VTA might be ultimately reflected in the activity of DA cells. Indeed, glutamatergic afferents to the VTA are thought to be important in regulating DA neuronal activity (Johnson et al., 1992; Overton and Clark, 1997), especially in mediating the switch from pacemaker-like to burst-firing pattern (Gariano and Groves, 1988; Svensson and Tung, 1989; Johnson et al., 1992; Murase et al., 1993; Zhang et al., 1994). Furthermore, the ability of DA cells to fire bursts of action potentials is thought to play a critical role in the phasic release of DA. Recent advances in DA sensors have enabled demonstrations of enhanced DA release at the terminals concurrent with phasic electrical activity at cell bodies, accompanying rewarding or alerting stimuli (Wightman and Robinson, 2002).

Thus, the activity-dependent release of endocannabinoids from VTA DA neurons might transiently suppress afferent excitation, via CB1-Rs, to a degree that would promote the coupling of inhibitory inputs and shape input integration as well as discharge pattern. In the end, by modulating glutamatergic afferents onto anterior VTA DA cells, endocannabinoids might contribute to the dynamic equilibrium existing between phasic and tonic DA release, which is considered to be responsible for the behaviorally relevant activation of the DA system (Schultz, 1997, 1998).

\section{References}

Ameri A, Wilhelm A, Simmet T (1999) Effects of the endogenous cannabinoid, anandamide, on neuronal activity in rat hippocampal slices. Br J Pharmacol 126:1831-1839.

Auclair N, Otani S, Soubrie P, Crepel F (2000) Cannabinoids modulate synaptic strength and plasticity at glutamatergic synapses of rat prefrontal cortex pyramidal neurons. J Neurophysiol 83:3287-3293.

Azad SC, Eder M, Marsicano G, Lutz B, Zieglgansberger W, Rammes G (2003) Activation of the cannabinoid receptor type 1 decreases glutamatergic and GABAergic synaptic transmission in the lateral amygdala of the mouse. Learn Mem 10:116-128.

Beltramo M, Piomelli D (2000) Carrier-mediated transport and enzymatic hydrolysis of the endogenous cannabinoid, 2-arachidonylglycerol. NeuroReport 11:1231-1235.

Beltramo M, Stella N, Calignano A, Lin SY, Makriyannis A, Piomelli D (1997) Functional role of high-affinity anandamide transport, as revealed by selective inhibition. Science 277:1094-1097.

Beltramo M, Rodriguez de Fonseca F, Navarro M, Calignano A, Gorriti MA, Grammatikopoulos G, Sadile AG, Giuffrida A, Piomelli D (2000) Reversal of dopamine $\mathrm{D}_{2}$-receptor responses by an anandamide transport inhibitor. J Neurosci 20:3401-3407.

Bonci A, Malenka RC (1999) Properties and plasticity of excitatory synapses on dopaminergic and GABAergic cells in the ventral tegmental area. J Neurosci 19:3723-3730.

Bonci A, Williams JT (1997) Increased probability of GABA release during withdrawal from morphine. J Neurosci 17:796-803.

Brenowitz SD, Regehr WG (2003) Calcium dependence of retrograde inhi- 
bition by endocannabinoids at synapses onto Purkinje cells. J Neurosci 23:6373-6784.

Brown SP, Brenowitz SD, Regehr WG (2003) Brief presynaptic bursts evoke synapse-specific retrograde inhibition mediated by endogenous cannabinoids. Nat Neurosci 6:1048-1057.

Chaytor AT, Martin PE, Evans WH, Randall MD, Griffith TM (1999) The endothelial component of cannabinoid-induced relaxation in rabbit mesenteric artery depends on gap junctional communication. J Physiol (Lond) 520:539-550.

Cheer JF, Kendall DA, Mason R, Marsden CA (2003) Differential cannabinoid-induced electrophysiological effects in rat ventral tegmentum. Neuropharmacology 44:633-641.

Chen K, Ratzliff A, Hilgenberg L, Gulyas A, Freund TF, Smith M, Dinh TP, Piomelli D, Mackie K, Soltesz I (2003) Long-term plasticity of endocannabinoid signaling induced by developmental febrile seizures. Neuron 39:599-611.

Christie MJ, Bridge S, James LB, Beart PM (1985) Excitotoxin lesions suggest an aspartatergic projection from rat medial prefrontal cortex to ventral tegmental area. Brain Res 333:169-172.

Debanne D, Guerineau NC, Gahwiler BH, Thompson SM (1996) Pairedpulse facilitation and depression at unitary synapses in rat hippocampus: quantal fluctuation affects subsequent release. J Physiol (Lond) 491:163-176.

De Petrocellis L, Bisogno T, Maccarrone M, Davis JB, Finazzi-Agro A, Di Marzo V (2001) The activity of anandamide at vanilloid VR1 receptors requires facilitated transport across the cell membrane and is limited by intracellular metabolism. J Biol Chem 276:12856-12863.

Deutsch DG, Glaser ST, Howell JM, Kunz JS, Puffenbarger RA, Hillard CJ, Abumrad N (2001) The cellular uptake of anandamide is coupled to its breakdown by fatty-acid amide hydrolase. J Biol Chem 276:6967-6973.

Devane WA, Hanus L, Breuer A, Pertwee RG, Stevenson LA, Griffin G, Gibson D, Mandelbaum A, Etinger A, Mechoulam R (1992) Isolation and structure of a brain constituent that binds to the cannabinoid receptor. Science 258:1946-1949.

Di Marzo V, Melck D, Bisogno T, De Petrocellis L (1998) Endocannabinoids: endogenous cannabinoid receptor ligands with neuromodulatory action. Trends Neurosci 21:521-528.

Di Marzo V, Hill MP, Bisogno T, Crossman AR, Brotchie JM (2000) Enhanced levels of endogenous cannabinoids in the globus pallidus are associated with a reduction in movement in an animal model of Parkinson's disease. FASEB J 14:1432-1438.

Fallon JH, Loughlin SE (1995) Substantia nigra. In: The rat nervous system (Paxinos G, ed.), pp 215-237. New York: Academic.

Felder CC, Glass M (1998) Cannabinoid receptors and their endogenous agonists. Annu Rev Pharmacol Toxicol 38:179-200.

French ED (1997) delta9-Tetrahydrocannabinol excites rat VTA dopamine neurons through activation of cannabinoid CB1 but not opioid receptors. Neurosci Lett 226:159-162.

Gariano RF, Groves PM (1988) Burst firing induced in midbrain dopamine neurons by stimulation of the medial prefrontal and anterior cingulate cortices. Brain Res 462:194-198.

Gatley SJ, Lan R, Volkow ND, Pappas N, King P, Wong CT, Gifford AN, Pyatt B, Dewey SL, Makriyannis A (1998) Imaging the brain marijuana receptor: development of a radioligand that binds to cannabinoid CB1 receptors in vivo. J Neurochem 70:417-423.

Gerdeman G, Lovinger DM (2001) Postsynaptic endocannabinoid release is critical to long-term depression in the striatum. Nat Neurosci 5:446-451.

Gessa GL, Melis M, Muntoni AL, Diana M (1998) Cannabinoids activate mesolimbic dopamine neurons by an action on cannabinoid CB1 receptors. Eur J Pharmacol 341:39-44.

Grace AA (1991) Phasic versus tonic dopamine release and the modulation of dopamine system responsivity: a hypothesis for the etiology of schizophrenia. Neuroscience 41:1-24.

Grillner P, Mercuri NB (2002) Intrinsic membrane properties and synaptic inputs regulating the firing activity of the dopamine neurons. Behav Brain Res 130:149-169.

Herkenham M, Lynn AB, de Costa BR, Richfield EK (1991) Neuronal localization of cannabinoid receptors in the basal ganglia of the rat. Brain Res 547:267-274.

Huang CC, Lo SW, Hsu KS (2001) Presynaptic mechanisms underlying cannabinoid inhibition of excitatory synaptic transmission in rat striatal neurons. J Physiol (Lond) 532:731-748.
Huang CC, Chen YL, Lo SW, Hsu KS (2002) Activation of cAMPdependent protein kinase suppresses the presynaptic cannabinoid inhibition of glutamatergic transmission at corticostriatal synapses. Mol Pharmacol 61:578-585.

Jaffe EH, Marty A, Schulte A, Chow RH (1998) Extrasynaptic vesicular transmitter release from the somata of substantia nigra neurons in rat midbrain slices. J Neurosci 18:3548-3553.

Johnson SW, North RA (1992) Two types of neurone in the rat ventral tegmental area and their synaptic inputs. J Physiol (Lond) 450:455-468.

Johnson SW, Seutin V, North RA (1992) Burst firing in dopamine neurons induced by $N$-methyl-D-aspartate: role of electrogenic sodium pump. Science 258:665-667.

Jones S, Kauer JA (1999) Amphetamine depresses excitatory synaptic transmission via serotonin receptors in the ventral tegmental area. J Neurosci 19:9780-9787.

Katz B (1971) Quantal mechanism of neural transmitter release. Science 173:123-126.

Kreitzer AC, Regehr WG (2001) Retrograde inhibition of presynaptic calcium influx by endogenous cannabinoids at excitatory synapses onto Purkinje cells. Neuron 29:717-727.

Kreitzer AC, Carter AG, Regehr WG (2002) Inhibition of interneuron firing extends the spread of endocannabinoid signaling in the cerebellum. Neuron 34:787-796.

Maccarrone M, Lorenzon T, Bari M, Melino G, Finazzi-Agro A (2000) Anandamide induces apoptosis in human cells via vanilloid receptors. Evidence for a protective role of cannabinoid receptors. J Biol Chem 275:31938-31945.

Maejima T, Hashimoto K, Yoshida T, Aiba A, Kano M (2001) Presynaptic inhibition caused by retrograde signal from metabotropic glutamate to cannabinoid receptors. Neuron 31:463-475.

Manzoni OJ, Williams JT (1999) Presynaptic regulation of glutamate release in the ventral tegmental area during morphine withdrawal. J Neurosci 19:6629-6636.

Marinelli S, Di Marzo V, Berretta N, Matias I, Maccarrone M, Bernardi G, Mercuri NB (2003) Presynaptic facilitation of glutamatergic synapses to dopaminergic neurons of the rat substantia nigra by endogenous stimulation of vanilloid receptors. J Neurosci 23:3136-3144.

Matsuda LA, Lolait SJ, Brownstein MJ, Young AC, Bonner TI (1990) Structure of a cannabinoid receptor and functional expression of the cloned cDNA. Nature 346:561-564.

Matsuda LA, Bonner TI, Lolait SJ (1993) Localization of cannabinoid receptor mRNA in rat brain. J Comp Neurol 327:535-550.

Mechoulam R, Ben-Shabat S, Hanus L, Ligumsky M, Kaminski NE, Schatz AR, Gopher A, Almog S, Martin BR, Compton DR (1995) Identification of an endogenous 2-monoglyceride, present in canine gut, that binds to cannabinoid receptors. Biochem Pharmacol 50:83-90.

Mechoulam R, Fride E, Ben-Shabat S, Meiri U, Horowitz M (1998) Carbachol, an acetylcholine receptor agonist, enhances production in rat aorta of 2-arachidonoyl glycerol, a hypotensive endocannabinoid. Eur J Pharmacol 362:R1-3.

Melis M, Camarini R, Ungless MA, Bonci A (2002) Long-lasting potentiation of GABAergic synapses in dopamine neurons after a single in vivo ethanol exposure. J Neurosci 22:2074-2082.

Mennerick S, Zorumski CF (1995) Paired-pulse modulation of fast excitatory synaptic currents in microcultures of rat hippocampal neurons. J Physiol (Lond) 488:85-101.

Murase S, Grenhoff J, Chouvet G, Gonon FG, Svensson TH (1993) Prefrontal cortex regulates burst firing and transmitter release in rat mesolimbic dopamine neurons studied in vivo. Neurosci Lett 157:53-56.

Ohno-Shosaku T, Maejima T, Kano M (2001) Endogenous cannabinoids mediate retrograde signals from depolarized postsynaptic neurons to presynaptic terminals. Neuron 29:729-738.

Ohno-Shosaku T, Shosaku J, Tsubokawa H, Kano M (2002a) Cooperative endocannabinoid production by neuronal depolarization and group I metabotropic glutamate receptor activation. Eur J Neurosci 15:953-961.

Ohno-Shosaku T, Tsubokawa H, Mizushima I, Yoneda N, Zimmer A, Kano M (2002b) Presynaptic cannabinoid sensitivity is a major determinant of depolarization-induced retrograde suppression at hippocampal synapses. J Neurosci 22:3864-3872.

Ohno-Shosaku T, Matsui M, Fukudome Y, Shosaku J, Tsubokawa H, Taketo MM, Manabe T, Kano M (2003) Postsynaptic M1 and M3 receptors are 
responsible for the muscarinic enhancement of retrograde endocannabinoid signalling in the hippocampus. Eur J Neurosci 18:109-116.

Okubo Y, Kakizawa S, Hirose K, Iino M (2001) Visualization of IP(3) dynamics reveals a novel AMPA receptor-triggered IP(3) production pathway mediated by voltage-dependent $\mathrm{Ca}(2+)$ influx in Purkinje cells. Neuron 32(1):113-122.

Overton PG, Clark D (1997) Burst firing in midbrain dopaminergic neurons. Brain Res Brain Res Rev 25:312-334.

Patel S, Hillard CJ (2003) Cannabinoid-induced Fos expression within A10 dopaminergic neurons. Brain Res 963:15-25.

Piomelli D, Beltramo M, Glasnapp S, Lin SY, Goutopoulos A, Xie XQ, Makriyannis A (1999) Structural determinants for recognition and translocation by the anandamide transporter. Proc Natl Acad Sci USA 96:5802-5807.

Piomelli D, Giuffrida A, Calignano A, Rodriguez de Fonseca F (2000) The endocannabinoid system as a target for therapeutic drugs. Trends Pharmacol Sci 21:218-224.

Rice ME, Cragg SJ, Greenfield SA (1997) Characteristics of electrically evoked somatodendritic dopamine release in substantia nigra and ventral tegmental area in vitro. J Neurophysiol 77:853-862.

Romero J, Garcia-Palomero E, Lin SY, Ramos JA, Makriyannis A, FernandezRuiz JJ (1996) Extrapyramidal effects of methanandamide, an analog of anandamide, the endogenous CB1 receptor ligand. Life Sci 58:1249-1257.

Romero J, Hillard CJ, Calero M, Rabano A (2002) Fatty acid amide hydrolase localization in the human central nervous system: an immunohistochemical study. Brain Res Mol Brain Res 100:85-93.

Ross RA, Gibson TM, Brockie HC, Leslie M, Pashmi G, Craib SJ, Di Marzo V, Pertwee RG (2001) Structure-activity relationship for the endogenous cannabinoid, anandamide, and certain of its analogues at vanilloid receptors in transfected cells and vas deferens. Br J Pharmacol 132:631-640.

Ryu SH, Cho KS, Lee KY, Suh PG, Rhee SG (1987) Purification and characterization of two immunologically distinct phosphoinositide-specific phospholipases C from bovine brain. J Biol Chem 262:12511-12518.

Salin PA, Malenka RC, Nicoll RA (1996) Cyclic AMP mediates a presynaptic form of LTP at cerebellar parallel fiber synapses. Neuron 16:797-803.

Schultz W (1997) Dopamine neurons and their role in reward mechanisms. Curr Opin Neurobiol 7:191-197.

Schultz W (1998) Predictive reward signal of dopamine neurons. J Neurophysiol 80:1-27.

Sesack SR, Pickel VM (1992) Prefrontal cortical efferents in the rat synapse on unlabeled neuronal targets of catecholamine terminals in the nucleus accumbens septi and on dopamine neurons in the ventral tegmental area. J Comp Neurol 320:145-151.

Shen M, Piser TM, Seybold VS, Thayer SA (1996) Cannabinoid receptor agonists inhibit glutamatergic synaptic transmission in rat hippocampal cultures. J Neurosci 16:4322-4334.

Smart D, Jerman JC (2000) Anandamide an endogenous activator of the vanilloid receptor. Trends Pharmacol Sci 21:134.

Smart D, Gunthorpe MJ, Jerman JC, Nasir S, Gray J, Muir AI, Chambers JK, Randall AD, Davis JB (2000) The endogenous lipid anandamide is a full agonist at the human vanilloid receptor (hVR1). Br J Pharmacol 129:227-230.

Stella N, Schweitzer P, Piomelli D (1997) A second endogenous cannabinoid that modulates long-term potentiation. Nature 388:773-778.

Sugiura T, Kondo S, Sukagawa A, Nakane S, Shinoda A, Itoh K, Yamashita A, Waku K (1995) 2-Arachidonoylglycerol: a possible endogenous cannabinoid receptor ligand in brain. Biochem Biophys Res Commun 215:89-97.

Sugiura T, Kodaka T, Nakane S, Miyashita T, Kondo S, Suhara Y, Takayama H, Waku K, Seki C, Baba N, Ishima Y (1999) Evidence that the cannabinoid CB1 receptor is a 2 -arachidonoylglycerol receptor. Structure- activity relationship of 2-arachidonoylglycerol, ether-linked analogues, and related compounds. J Biol Chem 274:2794-27801.

Svensson TH, Tung CS (1989) Local cooling of pre-frontal cortex induces pacemaker-like firing of dopamine neurons in rat ventral tegmental area in vivo. Acta Physiol Scand 136:135-136.

Szabo B, Dorner L, Pfreundtner C, Norenberg W, Starke K (1998) Inhibition of GABAergic inhibitory postsynaptic currents by cannabinoids in rat corpus striatum. Neuroscience 85:395-403.

Szabo B, Wallmichrath I, Mathonia P, Pfreundtner C (2000) Cannabinoids inhibit excitatory neurotransmission in the substantia nigra pars reticulata. Neuroscience 97:89-97.

Szabo B, Siemes S, Wallmichrath I (2002) Inhibition of GABAergic neurotransmission in the ventral tegmental area by cannabinoids. Eur J Neurosci 15:2057-2061.

Taber MT, Das S, Fibiger HC (1995) Cortical regulation of subcortical dopamine release. J Neurochem 65:1407-1410.

Thomas MJ, Malenka RC, Bonci A (2000) Modulation of long-term depression by dopamine in the mesolimbic system. J Neurosci 20:5581-5586.

Trettel J, Levine ES (2003) Endocannabinoids mediate rapid retrograde signaling at interneuron right-arrow pyramidal neuron synapses of the neocortex. J Neurophysiol 89:2334-2338.

Ungless MA, Whistler JL, Malenka RC, Bonci A (2001) Single cocaine exposure in vivo induces long-term potentiation in dopamine neurons. Nature 411:583-587.

Ungless MA, Singh V, Crowder TL, Yaka R, Ron D, Bonci A (2003) Corticotropin-releasing factor requires CRF binding protein to potentiate NMDA receptors via CRF receptor 2 in dopamine neurons. Neuron 39:401-407.

Varma N, Carlson GC, Ledent C, Alger BE (2001) Metabotropic glutamate receptors drive the endocannabinoid system in hippocampus. J Neurosci 21:RC188.

Vaughan CW, Connor M, Bagley EE, Christie MJ (2000) Actions of cannabinoids on membrane properties and synaptic transmission in rat periaqueductal gray neurons in vitro. Mol Pharmacol 57:288-295.

Wenger T, Moldrich G, Furst S (2003) Neuromorphological background of cannabis addiction. Brain Res Bull 61:125-128.

White R, Hiley CR (1998) The actions of the cannabinoid receptor antagonist, SR 141716A, in the rat isolated mesenteric artery. Br J Pharmacol 125:689-696

Wightman RM, Robinson DL (2002) Transient changes in mesolimbic dopamine and their association with "reward". J Neurochem 82:721-735.

Wilson RI, Nicoll RA (2001) Endogenous cannabinoids mediate retrograde signalling at hippocampal synapses. Nature 410:588-592.

Wilson RI, Kunos G, Nicoll RA (2001) Presynaptic specificity of endocannabinoid signaling in the hippocampus. Neuron 31:453-462.

Wise RA (1996) Neurobiology of addiction. Curr Opin Neurobiol 6:243-251.

Wu YN, Shen KZ, Johnson SW (1999) Presynaptic inhibition preferentially reduces in NMDA receptor-mediated component of transmission in rat midbrain dopamine neurons. Br J Pharmacol 127:1422-1430.

Zhang J, Chiodo LA, Freeman AS (1994) Influence of excitatory amino acid receptor subtypes on the electrophysiological activity of dopaminergic and nondopaminergic neurons in rat substantia nigra. J Pharmacol Exp Ther 269:313-321.

Zheng F, Johnson SW (2003) Metabotropic glutamate and muscarinic cholinergic receptor-mediated preferential inhibition of $N$-methyl-Daspartate component of transmissions in rat ventral tegmental area. Neuroscience 116:1013-1020.

Zygmunt PM, Petersson J, Andersson DA, Chuang H, Sorgard M, Di Marzo V, Julius D, Hogestatt ED (1999) Vanilloid receptors on sensory nerves mediate the vasodilator action of anandamide. Nature 400:452-457. 